\title{
Economics
}

2019; 8(4): 142-148

$\mathrm{http}: / / w w w . s c i e n c e p u b l i s h i n g g r o u p . c o m / \mathrm{j} / \mathrm{eco}$

doi: $10.11648 /$ j.eco.20190804.13

ISSN: 2376-659X (Print); ISSN: 2376-6603 (Online)

\section{Socioeconomic Determinants of Child Mortality (Under Age One): Reported by Mothers of Reproductive Age in Punjab, Pakistan}

\author{
Daud Rafique ${ }^{1,}$, , Muhammad Ali Bhatti ${ }^{1}$, Isaac Shahzad ${ }^{2}$, Suleman Shaukat ${ }^{1}$ \\ ${ }^{1}$ Department of Economics, Forman Christian College, Lahore, Pakistan \\ ${ }^{2}$ Bureau of Statistics, Government of Punjab, Lahore, Pakistan
}

Email address:

daudrafique@gmail.com (D. Rafique)

${ }^{*}$ Corresponding author

To cite this article:

Daud Rafique, Muhammad Ali Bhatti, Isaac Shahzad, Suleman Shaukat. Socioeconomic Determinants of Child Mortality (Under Age One): Reported by Mothers of Reproductive Age in Punjab, Pakistan. Economics. Vol. 8, No. 4, 2019, pp. 142-148.

doi: 10.11648/j.eco.20190804.13

Received: August 29, 2019; Accepted: October 31, 2019; Published: November 14, 2019

\begin{abstract}
The future of a nation lies in the hands of its children. Health of children should be the first priority of a nation. It is an indicator of social and economic development. Pakistan falls among high child mortality rate countries. The aim of this paper is to assess the socioeconomic determinants of child mortality in the Punjab. For this purpose, the study obtains data from Multiple Indicator Cluster Survey (2014), conducted by Punjab Bureau of statistics. The data were collected with the help of well-designed three questionnaires from 38,405 households of Punjab. The STATA is used to apply Logistic model to determine the factors affecting child mortality. The dependent variable is dichotomous in nature based on this question "Have you ever given birth to a boy or girl who was born alive but later died?" and response is either yes or no. According to the empirical results of the study, area of residence, source of drinking water, women ever attended school and their level of education, women media awareness, women smoking and wealth quintiles are important socioeconomic determinants of child mortality. But comparatively, wealth quintiles have greater influence on reducing child mortality. The study suggests some policies to improve the situation, e.g., allocation of more budget for health, initiative of health care programs for women and infant, particularly in rural areas of Punjab.
\end{abstract}

Keywords: Infant, Poverty, Household, Logistic Regression, Poverty Status and Poverty Factors

\section{Introduction}

Children are the future of a nation. They play an important role in nation building. Healthy children mean healthy future of a nation. Infant and child mortality has been widely used in the literature as indicators of the child health. Infant mortality has inverse relationship with socioeconomic development as high infant mortality indicates poor government health policies and low socio-economic development. Like other developing countries, Pakistan is also facing high infant mortality rate. Health system in Pakistan consists of private and public health facilities. The public health sector is divided at federal, provisional and districts levels. The public health facilities are provided through well-organized network of rural health centers, dispensaries, basic health centers, tehsil and district head quarter hospitals. After 18th Amendment, the provisional governments of Pakistan are responsible for their health care programs [5]. According to Economic Survey of Pakistan (2017), Pakistan has an estimated population of 207.77 million in 2017. Punjab has an estimated population of 110.01 million. Out of which, $63.29 \%$ and $36.71 \%$ reside in rural and urban areas, respectively. The proportion of infant is $2.5 \%$ (Punjab Health Department). The infant mortality rate is 62 per 1000 live births. UNICEF states that male infant mortality is higher than female infant mortality in Pakistan. Since 1947, Pakistan has been facing poor socio-economic conditions which cause health issues like high infant mortality rate, maternal mortality, etc. In 1950s, infant mortality declined rapidly from 154 to 121 and it further decreased to 104 in 1970s (UN Data). But still lot of work has to be done because in Pakistan a baby dies in every 
three minutes. In order to get social development, health is one of the most important elements. Many nations are facing the challenge of providing affordable quality health care to their people. Pakistan stands 2 nd among top 10 those countries where nearly $2 / 3$ of all deaths are from pre-term birth complications. Without a major push to reduce these deaths, it will not be possible to achieve the sustainable development goal (UNICEF).

Infant Mortality is widely used as a measure of health status and quality of health care of a country. Improvement in health status accelerates socio-economic development. For children health as well as for social development, infant mortality is important and valuable indicator. Infant mortality is worldly known issue. To tackle this serious issue, it was included in MDGs which were signed by leaders of 189 countries. The SDGs is to bring infant mortality to 12 per 1000 live births by 2030. In Pakistan, WHO is working in collaboration with government of Pakistan at federal as well as provincial levels. Pakistan is the sixth most populous country in the world with 207.7 million estimated population. According to the UNICEF, 2.6 million newborn babies do not survive in the world every year. Pakistan is ranked $1^{\text {st }}$ around the world where newborn babies do not survive their first month of life. It shows that Pakistan has poor health conditions for infants. Therefore, infant mortality is considered to be a crucial issue in Pakistan. High mortality has a very negative affect on the performance of health sector and hence on the economic growth of Pakistan in the long run. The study focuses on Punjab, the largest population wise-province, more than 50 percent population of the country is living in it. Punjab contributes 59 percent in the total GDP of Pakistan. It also performs a large share in the development of the country. It is revealed that women education, water sanitation and wealth index reduce child mortality. According to the researcher, socioeconomic and maternal factors are strongly associated with child mortality [1]. Factors related gender like, women education can decline child mortality. The study investigated individual, household and clustered socioeconomic features of five developing countries in South Asia and Sub-Saharan Africa. Their finding suggests that as income inequality increases it adversely affects the distribution of household income [6].

Higher socioeconomic groups have lower risk of infant mortality. They were able to maintain a health advantage [9].

It is also revealed that child mortality rate was high in rural areas [2]. A study found that regional variations exist in child mortality. Child born in the richest household has lower chances of child mortality compared to those who born in poorest household. The child and maternal health can be greatly influenced by increasing the sustainable access to improved source of drinking water and hygiene. The diarrheal disease of almost half a million children every year can be attributed to unsafe water and poor sanitation [10].

2017 David Increase in women's schooling will decreases infant and child mortality. Maternal education has potential to decreases fertility especially in rural areas.

Similarly, child mortality was higher among un-educated women. Education has directly and indirectly linked with child mortality. The uneducated women are not well aware with hygienic issues. They do not have information regarding marriage age [3].

The results shows the strong impacts of sanitation on child net-nutrition and infant mortality in India. Timeline of this research contained 4 events. Feb-2004, August-2004 and 2005-August. Child height of aged under 5 years was used as a dependent variable. Simple regression analysis was used. The main finding of this result was, sanitation of water reduces infant mortality. It was also shown that village sanitation has positive association with infant mortality. Half of the village population in rural India defecate in the open. It has strong consequences for early life health and human capital for infants in developing countries [7].

There are no detail studies on child mortality in Punjab. This dataset is the latest available and comprehensive grassroot data on Punjab which covers all 36 districts of Punjab. This analysis will help to recommend policies at grass root level depending upon factors which are more effective in Punjab. Its objectives are to achieve SDGs, decrease child mortality, identify causes and determinants of child mortality in Punjab. Identifying and determining child mortality factors can be used as a source of information for further studies. Thus, this study is an attempt to identify the major factors of child mortality.

The economic development of a country depends on health status of its people. The welfare of a society can be affected by different factors. These factors make hard for them to fulfill their basic needs. Identifying major factors affecting child mortality is important to decide what action should be taken to reduce it. The main goal of the study is to assess socioeconomic factors that affect the child mortality in the study area.

\section{Methods}

The study obtains data from Multiple Indicator Cluster Survey (MICS), 2014, conducted by Punjab Bureau of Statistics, Planning and Development, Government of Punjab in collaboration with UNICEF is chosen for this Crosssectional study. This survey is conducted with the help of three questionnaires, i.e., questionnaires for household, questionnaires for individual women (age 15-49) and questionnaires for children under five. In this survey, 41,413 households are sampled, out of these 39,333 households are occupied and out of these 38,403 household are successfully interviewed with response rate of 97.6 percent. Out of 61,286 women (age 15-49), 53,668 women are interviewed successfully with a response rate of 88 percent. Further a two stage, stratified cluster sampling approach was followed in this survey At stage one, enumeration blocks included in both rural and urban areas are known as primary sampling unit. At stage two, 20 households from both urban and rural sample areas used systematic technique with a random start based on the listing done by the field staff of primary sampling unit. Income or consumption data is absent, MICS used household assets to design a wealth index through principal component.

In order to decrease the recall bias in Multiple Indicator Cluster Survey (MICS), information regarding variables for instance women education, women ever attended school, 
women mass media awareness etc. was asked for women who ever had birth and have infant mortality. Data Set was constructed by merging files from women questionnaire and their children questionnaire and had some missing values that can affect the analysis because mode of multivariate analysis, which does not capture the missing values, these missing values can also disturb the other variables. At initial stage, the sample size was 31,083 women but after removing the missing values, it reduces to 30,541 women. Hence, a file was prepared for the children under age one (Infant children).

\section{Logistic Regression Model}

In this study, the dependent variable is dichotomous in nature based on this question "Have women aged 15-49 years ever given birth to a boy or girl who was born alive but later died?" and response is either yes or no. Due to this dichotomous nature of dependent variable, the study applied logistic regression for the empirical analysis. An outcome of dead child is defined as a dichotomous variable with value of one for dead and zero for survive.

The logit model is given below:

$$
\ln \left[\frac{p}{1-p}\right]=\alpha_{0}+\alpha_{1} X_{1}+\alpha_{2} X_{2}+\alpha_{3} X_{3} \ldots \alpha_{k} X_{k}
$$

$\mathrm{P}=$ Probability to die.

$1-\mathrm{P}=$ Probability to survive.

$\mathrm{X}_{1-\mathrm{k}}=$ Explanatory variables

\section{Result and Discussion}

\subsection{Descriptive Statistics Result}

The descriptive statistics shows the overall picture of data set. The Table includes the information on the distribution of women who ever married and had child mortality. It includes the frequencies and percentages of child mortality, wealth quintiles, regions of Punjab, residence, women ever attended school, women education, women media awareness, women smoking, women age at her first infant birth and source of drinking water. Table 1 shows that incidence of child mortality is 26.4 percent in Punjab. In this study wealth quintile is used in order to consider the resources available to the members of a household. Wealth quintile is divided into five groups from the poorest to the richest. In Punjab, 19.2 percent of women belong to the poorest family status and 19.8 percent of women belong to poorer family status. So almost 39 percent of the women live in poverty. The table shows that 21.5 percent and 18.6 percent women live in richer and richest quintiles, respectively. Wealth is expected to have a significant impact on infant mortality. With high income, child mortality reduces. In Punjab, 63.5 percent women lives in rural areas. In rural areas women have less resources as compared to urban areas. Women education is another key socio-economic determinant of infant mortality. Table 1 shows considerable difference in education level of women. This variable is classified as none-education, primary, middle, matric and higher education. These categories may also include school drop-out. For instance, a respondent whose highest level is reported as primary may have completed only two years of schooling. So, these levels do not indicate that the women had finished that level. In Punjab majority of the women are uneducated, 51.5 percent women did not ever attended school. Women education is considered to be a one of the most important and powerful aspect.

Table 1. Frequency Distribution of Women Who Ever Born Child.

\begin{tabular}{|c|c|c|c|c|}
\hline \multirow{3}{*}{ Sr. No } & \multirow{3}{*}{ Variables } & \multirow{2}{*}{ Description } & \multicolumn{2}{|l|}{ Punjab } \\
\hline & & & No. & $\%$ \\
\hline & & Total & 30541 & 100 \\
\hline \multirow{2}{*}{1.} & \multirow{2}{*}{ Child mortality } & No & 22478 & 73.6 \\
\hline & & Yes & 8063 & 26.4 \\
\hline \multirow{5}{*}{2.} & \multirow{5}{*}{ Wealth quintiles } & Poorest & 5874 & 19.2 \\
\hline & & Poorer & 6048 & 19.8 \\
\hline & & Middle & 6347 & 20.8 \\
\hline & & Richer & 6581 & 21.5 \\
\hline & & Richest & 5691 & 18.5 \\
\hline \multirow{2}{*}{3.} & \multirow{2}{*}{ Residence } & Rural & 19390 & 63.5 \\
\hline & & Urban & 11151 & 36.5 \\
\hline \multirow{2}{*}{4.} & \multirow{2}{*}{ Women ever attended school } & No & 15696 & 51.4 \\
\hline & & Yes & 14845 & 48.6 \\
\hline \multirow{5}{*}{5.} & \multirow{5}{*}{ Women education } & None & 15863 & 51.9 \\
\hline & & Primary & 5462 & 17.9 \\
\hline & & Middle & 2646 & 8.7 \\
\hline & & Matric & 3499 & 11.5 \\
\hline & & Higher & 3071 & 10.1 \\
\hline \multirow{2}{*}{6.} & \multirow{2}{*}{ Women media awareness } & No & 10827 & 35.35 \\
\hline & & Yes & 19714 & 64.5 \\
\hline \multirow{2}{*}{7.} & \multirow{2}{*}{ Women smoking } & No & 29571 & 96.8 \\
\hline & & Yes & 970 & 3.2 \\
\hline
\end{tabular}




\begin{tabular}{|c|c|c|c|c|}
\hline \multirow{3}{*}{ Sr. No } & \multirow{3}{*}{ Variables } & \multirow{2}{*}{ Description } & \multicolumn{2}{|c|}{ Punjab } \\
\hline & & & No. & $\%$ \\
\hline & & Total & 30541 & 100 \\
\hline \multirow{5}{*}{8.} & \multirow{5}{*}{ Women age at her first child birth } & $12-18$ & 5150 & 16.9 \\
\hline & & $19-25$ & 17545 & 57.4 \\
\hline & & $26-32$ & 5898 & 19.3 \\
\hline & & $33-39$ & 590 & 1.9 \\
\hline & & $40 \&$ above & 1358 & 4.4 \\
\hline \multirow{2}{*}{9.} & \multirow{2}{*}{ Source of drinking water } & Unimproved & 1462 & 4.8 \\
\hline & & Improved & 29079 & 95.2 \\
\hline
\end{tabular}

According to results of chi-square analysis of child mortality, it is observed that child mortality has a significant association with all the determinants that are used in this study. The significance between child mortality and other variables is according to the theory. From Table 2, it is seen that child mortality is strongly associated with higher level of women education, women ever attended school, Higher level of wealth status, women awareness of media, lower level of smoking women, source of drinking water, residence and mother's age at first child birth.

Table 2. Hypothesis testing and chi-square values of independent variables.

\begin{tabular}{|c|c|c|c|}
\hline Hypothesis & Value & Probability & Result \\
\hline High level of education in women plays a significant role in determining child mortality & 1351.396 & 0.000 & Associated \\
\hline Women who ever had attended school plays a significant role in determining child mortality & 1145.58 & 0.000 & Associated \\
\hline Different level of wealth status plays a significant role in determining child mortality & 819.394 & 0.000 & Associated \\
\hline Media awareness among women play a significant role in determining child mortality & 231.437 & 0.000 & Associated \\
\hline Women who do not smoke play a significant role in determining child mortality & 143.658 & 0.000 & Associated \\
\hline Safe and cleaning source of drinking water has a significant role in determining child mortality & 5.332 & 0.021 & Associated \\
\hline Child born in rural area has a significant impact in determining child mortality & 205.688 & 0.000 & Associated \\
\hline
\end{tabular}

Table 3 includes information on the distribution of the women which had child mortality according to the women education, women who ever attended school, wealth quintiles, women who use to smoke, water facilities, women age at her first child birth, women media awareness and source of drinking water. The analysis is expended to urban and rural areas. In Punjab, rural women who belong to poorest family status had registered 36.5 percent of mortality cases. As the family status improves, the infant mortality decreases to only 2.8 percent. The table shows that major portion of infant mortality belongs to rural poorest class i.e., 50 percent. According to our sample, more than half of the population of Punjab is poor. Mostly rural people are poor. Their male and females both work in agriculture sector.

Table 3. Descriptive analysis of child mortality on rural-urban base.

\begin{tabular}{|c|c|c|c|c|c|c|c|}
\hline \multirow{5}{*}{ Variable } & \multirow{5}{*}{ Description } & \multicolumn{6}{|c|}{ Women who have child mortality } \\
\hline & & \multicolumn{6}{|c|}{ No. $=8063$} \\
\hline & & \multicolumn{2}{|c|}{ Rural } & \multicolumn{2}{|c|}{ Urban } & \multicolumn{2}{|l|}{ Total } \\
\hline & & No. & $\%$ & No. & $\%$ & No. & $\%$ \\
\hline & & 5651 & 70 & 2421 & 30 & 8063 & 100 \\
\hline \multirow{2}{*}{ Women ever attended school } & No & 4257 & 75.3 & 1190 & 49.3 & 5447 & 67.6 \\
\hline & Yes & 1394 & 24.7 & 1222 & 50.7 & 2616 & 32.4 \\
\hline \multirow{4}{*}{ Women education } & None & 4291 & 75.9 & 1204 & 49.9 & 5495 & 68.2 \\
\hline & Middle & 240 & 4.2 & 218 & 9 & 458 & 5.7 \\
\hline & Matric & 207 & 3.7 & 285 & 11.8 & 492 & 6.1 \\
\hline & Higher & 122 & 2.2 & 210 & 8.7 & 332 & 4.1 \\
\hline \multirow{2}{*}{ Women media awareness } & No & 2911 & 51.5 & 508 & 21.1 & 3419 & 42.4 \\
\hline & Yes & 2740 & 48.5 & 1904 & 78.9 & 4644 & 57.6 \\
\hline \multirow{2}{*}{ Women smoking } & No & 5336 & 94.4 & 2309 & 95.7 & 7645 & 94.8 \\
\hline & Yes & 315 & 5.6 & 103 & 4.3 & 418 & 5.2 \\
\hline \multirow[t]{2}{*}{ Regions of Punjab } & Central & 2081 & 36.8 & 1084 & 44.9 & 3165 & 39.3 \\
\hline & Northern & 894 & 15.8 & 439 & 18.2 & 1333 & 16.5 \\
\hline \multirow{5}{*}{ Wealth quintile } & Poorest & 2063 & 36.5 & 94 & 3.9 & 2157 & 26.8 \\
\hline & Poorer & 1626 & 28.8 & 248 & 10.3 & 1874 & 23.2 \\
\hline & Middle & 1193 & 21.1 & 502 & 20.8 & 1695 & 21 \\
\hline & Richer & 611 & 10.8 & 873 & 36.8 & 1484 & 18.4 \\
\hline & Richest & 158 & 2.8 & 695 & 28.8 & 853 & 10.6 \\
\hline \multirow{2}{*}{ Source of drinking water } & Un-improved source & 148 & 2.6 & 200 & 8.3 & 348 & 4.3 \\
\hline & Improved source & 5503 & 97.4 & 2212 & 91.7 & 7715 & 95.7 \\
\hline
\end{tabular}




\begin{tabular}{|c|c|c|c|c|c|c|c|}
\hline \multirow{5}{*}{ Variable } & \multirow{5}{*}{ Description } & \multicolumn{6}{|c|}{ Women who have child mortality } \\
\hline & & \multicolumn{6}{|c|}{ No. $=8063$} \\
\hline & & \multicolumn{2}{|c|}{ Rural } & \multicolumn{2}{|c|}{ Urban } & \multicolumn{2}{|l|}{ Total } \\
\hline & & No. & $\%$ & No. & $\%$ & No. & $\%$ \\
\hline & & 5651 & 70 & 2421 & 30 & 8063 & 100 \\
\hline \multirow{5}{*}{ Women age at first birth } & $12-18$ & 1331 & 23.6 & 508 & 21.1 & 1839 & 22.8 \\
\hline & $19-25$ & 3031 & 53.6 & 1391 & 57.7 & 4422 & 54.8 \\
\hline & $26-32$ & 868 & 15.4 & 340 & 14.1 & 1208 & 15 \\
\hline & $33-39$ & 77 & 1.4 & 24 & 1 & 101 & 1.3 \\
\hline & $40 \&$ above & 344 & 6.1 & 149 & 6.2 & 493 & 6.1 \\
\hline
\end{tabular}

\subsection{Logistic Regression Analysis of Child Mortality}

Two models are formed for empirical analysis. Table 4 represents the odds ratios and their corresponding p-values. The odd ratios indicate the change in odds of infant mortality for a one-unit change in independent variable. These odd ratios are expected change in odds of infant mortality as compared to reference category. If odd ratio is equal to one, it indicates no relationship, odd ratios greater than one indicate increase in odds or a positive relationship and odd ratios under one indicates negative relationship or decrease in the odds. First model gives results of overall Punjab. First Model of Punjab includes all explanatory variables except women media awareness and women ever attended school. Second Model of Punjab excludes women education level and impact of wealth quintiles.

Wealth quintiles are highly significant in Model 1. The odd ratios of wealth quintiles suggest that the probabilities of infant survival increase with the increase in wealth. For example, odd ratio of wealth quintile (poorer), 0.85 indicates that the chances of infant mortality are expected to be 15 percent lesser if infant is born in poorer household compared to the poorest wealth quintile.

Results of the study imply that source of drinking water has significant impact on infant mortality. It has less than one odd ratio i.e., (0.84). Results of Model 1, suggests that if other things remain constant, infant of household who uses improved source of water have 16 percent less chances of infant death as compared to infants whose household uses unimproved source of drinking water. In Pakistan water borne diseases are very common. The incidence of infant mortality is less when the source of water is clean. Unclean drinking water causes harmful diseases. In Punjab, large number of villages have ponds which have turned into major health hazards. These ponds have become source of water borne diseases because source of water of these ponds is storm water or village waste water [13].

Education of the women is another socioeconomic variable included in the Model (1). It has a very strong impact on survival chances of infant. Results of Table 4 show that level of education of women is statistically significant in all categories. The odd ratio of women with primary education is significant and its value is 0.65 . It suggests that women with primary level of education have 35 percent less likely of their infant die compared to those women who have no education.

The results for women who smoke show an odd ratio 1.74. It suggests that survival of the infants decreases by 74 percent if women smoke compared to those women who do not smoke, examined the importance of education [4]. The study shows that educated women have more health knowledge as well as lower infant mortality.

The variable under geographic region is the area of residence, i.e., rural and urban is also an important determinant of infant mortality. The odd ratio of urban is 1.04 suggesting that infants born in urban areas are expected to die more compared to their counterpart in the rural areas. However, this ratio is not significant, found similar results in the study [8]. In Model (2), socioeconomic variables, i.e., wealth quintiles and women education level are excluded. As far area of residence is concern, the results are totally different in model (2) as compared to model (1). The odd ratio of urban area is significant and less than one (0.86). It indicates that women in urban areas are 14 percent less likely to have infant mortality as compared to their rural counterparts. It shows that large rural-urban disparities exist if wealth quintile is not controlled in the model. Urban women have easy access to health facilities. Therefore, they have low chances of infant mortality. In other words, more health facilities are available in urban areas as compared to rural areas of Punjab.

"Smoking is injurious to health." It is a universal truth. Women-smoking significantly affect infant mortality. The odd ratio is 1.8 indicating that infant's death is to be 1.8 times higher if mother smoke. In Model (2), odd ratio of urban residence is 0.86 . It means infant mortality risk is 14 percent less in urban area compared to rural area. In urban areas, women have more facilities. They enjoy healthy life compared to rural women. Urban women have basic and primary health facilities. 
Table 4. Logistic Regression analysis of infant mortality.

\begin{tabular}{|c|c|c|c|c|c|}
\hline \multirow{4}{*}{ Serial No. } & \multirow{4}{*}{ Variables } & \multicolumn{2}{|l|}{ Punjab } & \multicolumn{2}{|l|}{ Punjab } \\
\hline & & \multicolumn{2}{|l|}{$\mathrm{N}=\mathbf{3 0 5 4 1}$} & \multicolumn{2}{|l|}{$N=30541$} \\
\hline & & \multicolumn{2}{|l|}{ Model (1) } & \multicolumn{2}{|l|}{ Model (2) } \\
\hline & & Odds Ratio & P-value & Odds Ratio & P-value \\
\hline \multirow{6}{*}{1.} & Wealth quintiles & & & & \\
\hline & Poorest (Reference) & & & & \\
\hline & Poorer & 0.8546 & 0.000 & & \\
\hline & Middle & 0.7995 & 0.000 & & \\
\hline & Richer & 0.7558 & 0.000 & & \\
\hline & Richest & 0.6023 & 0.000 & & \\
\hline \multirow{3}{*}{2.} & Source of drinking water & & & & \\
\hline & Unimproved source (Reference) & & & & \\
\hline & Improved source & 0.8469 & 0.012 & .9031 & 0.118 \\
\hline \multirow{6}{*}{3.} & Women age at first birth & & & & \\
\hline & 12-18 (Reference) & & & & \\
\hline & $19-25$ & 0.7038 & 0.000 & 0.6850 & 0.000 \\
\hline & $26-32$ & 0.5895 & 0.000 & 0.5470 & 0.000 \\
\hline & $33-39$ & 0.4527 & 0.000 & 0.4191 & 0.000 \\
\hline & 40 and above & 1.038 & 0.566 & 1.050 & 0.449 \\
\hline \multirow{3}{*}{4.} & Women ever attended school & & & & \\
\hline & No (Reference) & & & & \\
\hline & Yes & & & 0.4625 & 0.000 \\
\hline \multirow{6}{*}{5.} & Women education & & & & \\
\hline & None (Reference) & & & & \\
\hline & Primary & 0.6527 & 0.000 & & \\
\hline & Middle & 0.4668 & 0.000 & & \\
\hline & Matric & 0.3999 & 0.000 & & \\
\hline & Higher & 0.3373 & 0.000 & & \\
\hline \multirow{3}{*}{6.} & Women media awareness & & & & \\
\hline & No (Reference) & & & & \\
\hline & Yes & & & 0.9292 & 0.013 \\
\hline \multirow{3}{*}{7.} & Women smoking & & & & \\
\hline & No (Reference) & & & & \\
\hline & Yes & 1.7467 & 0.000 & 1.8235 & 0.000 \\
\hline \multirow{3}{*}{8.} & Residence & & & & \\
\hline & Rural (Reference) & & & & \\
\hline & Urban & 1.0406 & 0.258 & 0.8682 & 0.000 \\
\hline Constant & & 0.9460 & 0.463 & 0.8743 & 0.068 \\
\hline
\end{tabular}

\section{Conclusion}

Based on the collected data from the study area, proportion of women who had child mortality was $26.4 \%$. The result of logistic regression showed that wealth quintiles, source of drinking water, women age at her first birth, women ever attended school, women education, women media awareness, women smoking and region of residence have significant effect on the child mortality of in the study area based on the collected data from the study area. Based on identified factors, the researchers recommend that government of Punjab may allocate more budget for health. Government may initiate maternal and child health programs for improvement of quality and health services at primary health care particularly for rural women. Lastly, Government may also increase investment in education-particularly for girls' education.

\section{References}

[1] Agha, S. (2000). The Determinants of Infant Mortality in Pakistan. Socail Science and Medicine, 51, 199-208.

[2] Al jumaily, H. F., Al-Amin, M. M., \& Hantush, M. M. (2013). Infant Mortality rate in Al-Ramadi Province from 2000 through 2010, retrospective study. Health, 5 (2), 292297.

[3] Chowdhury, Q. H., Islam, R., \& Hossain, K. (2010). Socioeconomic Determinants of Neonatal, Postnatal, Infant and Child Mortality. International Journal of Sociology and Anthropology, 2 (6), 118-125.

[4] Clark, S., Bruce, J., \& Dude, A. (2006). Protecting Young Women from HIV/AIDS: The case against Child and Adolscent Marriage. International Family Planning Perspective, 32 (2), 79-88. 
[5] Economic Adviser's Wing, F. D. (2016-2107). Pakistan Economic Survey. Islamabad: Economic Adviser's Wing, Finance Division, Government of Pakistan. Retrieved from http://www.finance.gov.pk/survey/chapters_17/Pakistan_ES_2 016_17_pdf.

[6] Harttgen, K., \& Misselhorn, M. (2006). A Multilevel Approach to Explain Child Mortality and Undernutrition in South Asia and Sub-Saharan Africa. Ibero America Institute for Economic Research Discussion Paper No. 152.

[7] Hammer, J., \& Spears, D. (2016). Village sanitation and child health: Effects and external validity in arandomized field experiment in rural India. Journal of Health Economics, 48, $135-148$.

[8] Hossain, B. (2015). Women Empowerment and Infant Mortality in Bangladesh. Journal of Developing Areas.

[9] Molitoris, J. (2017). Disparities in death: Inequality in CauseSpecific Infant and Child Mortality in Stockholm, 1878-1926. Demographic Research, 455-500.
[10] Mustafa, H. E., \& Odimegwu, C. (2008). Socioeconomic Determinants of Infant Mortality in Kenya: Analysis of Kenya DHS 2003. Journal of Humanities and Socail Science, 2 (2).

[11] PMNCH. (2012). Reaching Child Brides. PMNCH Knowledge Summary \#22. Retrieved from http://www.who.int/pmnch/topics/part_publications/KS22_Sta ndalone_low.pdf

[12] Punjab, G. o. (2015). Punjab Health Sector Plan 2018: Building a Healthier Punjab. Lahore: Government of Punjab. Retrieved from http://www.pndpunjab.gov.pk/system/files/Punjab_Health_Sec tor_Plan_2018_0.pdf

[13] Shapiro, D., \& Teniku, M. (2017). Women's Education, Infant and Child Mortality, and Fertility decline in Urban and Rural Sub-Saharan Africa. Demographic Research, 669-708.

[14] UN (2007). The Millennium Development Goals Report. United Nations Department of Economic and Social Affairs DESA. 